\title{
Myocardial strain imaging with radial acquisitions (SIRA) reduces tag fading compared to Cartesian sampling
}

\author{
Edward Hulten ${ }^{1,3^{*}}$, Ravi V Shah ${ }^{1,2}$, Siddique Abbasi ${ }^{1}$, Tomas Neilan ${ }^{1,2}$, Jiazuo Feng ${ }^{1}$, John Groarke ${ }^{1}$, \\ Alfonso H Waller ${ }^{1}$, Ron Blankstein ${ }^{1}$, Raymond Y Kwong ${ }^{1}$, Michael Jerosch-Herold ${ }^{1}$
}

From 17th Annual SCMR Scientific Sessions

New Orleans, LA, USA. 16-19 January 2014

\section{Background}

Myocardial tagging is considered a gold-standard technique to derive myocardial strain using cardiac magnetic resonance (CMR) in large epidemiologic studies. Nevertheless technical limitations related to tag line fading (via T1 relaxation) limit generalizability and reproducibility of this technique. Our purpose was to test myocardial tagging with radial $k$-space acquisition against routinely utilized Cartesian k-space sampling techniques, in order to potentially minimize tag-line fading over the cardiac cycle.

\section{Methods}

We compared a new tagging sequence with radial acquisitions for cardiac MRI to a routinely-utilized clinical tagging sequence with Cartesian sampling. Both sequences were added pre-contrast to routine clinical scans of 14 patients. The per phase change in grayscale contrast due to T1 relaxation ("tag fading") of tagged myocardium was modeled using a non-linear fit with maximum likelihood estimation to an exponential decay curve and compared between groups. Peak Eulerian circumferential strain (Ecc) was compared using HARP software.

\section{Results}

14 patients (mean age $54 \pm 16$ years and $36 \%$ were men) and mean left ventricular ejection fraction $53 \pm 16 \%$ (LVEF) were included. Tag fading differed significantly between radial and Cartesian sampling; the exponential decay coefficient was $-0.045 \pm 0.011$ for the Cartesian and significantly higher than the-decay coefficient value of $0.029 \pm 0.007$ for radial read-outs $(p<0.001)$. Due to

${ }^{1}$ Noninvasive Cardiovascular Imaging, Brigham and Women's Hospital and Harvard Medical School, Boston, Massachusetts, USA

Full list of author information is available at the end of the article less tag fading myocardial strain could be evaluated for more segments acquired with radial, compared to Cartesian read-outs $(\mathrm{p}<0.001)$. The intra-observer reliability for Ecc was higher for radial $(r=0.99, p<0.001)$ than Cartesian $(\mathrm{r}=0.86, \mathrm{p}=<0.001)$ images $(\mathrm{p}=0.002$ for comparison). The bias was $0.9 \%$ and limits of agreement -4.1 to $6.0 \%$ with concordance $=0.86(\mathrm{p}<0.001)$ for Ecc-radial versus Ecc-Cartesian. Both tagging methods correlated with LVEF, $r=-0.86(p<0.001)$ for Ecc-radial versus $r=-0.83(p<0.001)$ for Ecc-Cartesian.

\section{Conclusions}

Radial k-space acquisition with very low flip-angle excitations leads to better reliability for myocardial strain relative to standard, widely employed Cartesian readouts, while maintaining good signal-to-noise. Radial k-space

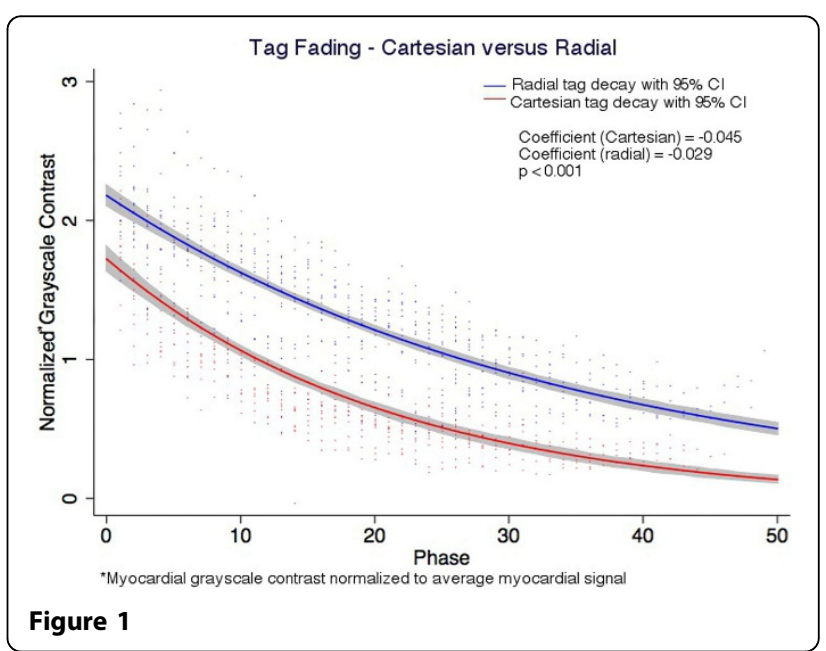


acquisition is a promising new approach for evaluating myocardial strains using MRI.

\section{Funding}

None.

\section{Authors' details}

${ }^{1}$ Noninvasive Cardiovascular Imaging, Brigham and Women's Hospital and Harvard Medical School, Boston, Massachusetts, USA. 'Division of Cardiology, Massachusetts General Hospital and Harvard Medical School, Boston, Massachusetts, USA. ${ }^{3}$ Cardiology, Walter Reed National Military Medical Center, Bethesda, Maryland, USA.

Published: 16 January 2014

doi:10.1186/1532-429X-16-S1-P35

Cite this article as: Hulten et al: Myocardial strain imaging with radial acquisitions (SIRA) reduces tag fading compared to Cartesian sampling. Journal of Cardiovascular Magnetic Resonance 2014 16(Suppl 1):P35.

Submit your next manuscript to BioMed Central and take full advantage of:

- Convenient online submission

- Thorough peer review

- No space constraints or color figure charges

- Immediate publication on acceptance

- Inclusion in PubMed, CAS, Scopus and Google Scholar

- Research which is freely available for redistribution

Submit your manuscript at www.biomedcentral.com/submit 